\title{
Sexual dysfunction in married female patients on antidepressants: A Cross Sectional Observational study from Patna medical college and hospital
}

\author{
Vivek Pratap Singh', Abhishek Pratap Singh ${ }^{2}$, Narendra Pratap Singh ${ }^{3}$ \\ ${ }^{1}$ Senior Resident, ${ }^{3}$ Professor and Head, Department of Psychiatry, Patna Medical College and Hospital, Patna, Bihar. \\ 2Junior Resident, Department of General Medicine, Patna Medical College and Hospital, Patna, Bihar.
}

Background: Clinicians and patients now have a broad variety of antidepressants to choose from, due to an ever-growing pharmacopoeia. However, one of the most significant considerations preventing antidepressant use is their side effects, one of which is sexual dysfunction. This issue has a negative impact on the patient's quality of life which can contribute to clinical non-adherence in long-term therapies. Aims and Objectives: The objective of this research was to look into the characteristics of sexual dysfunction in married female antidepressant patients and patterns of sexual dysfunctions in female patients receiving antidepressants. Materials and Methods: It was Cross-sectional observational study. The study was conducted in the department of Psychiatry, Patna Medical College and Hospital at Patna. The Departmental Research Committee accepted the report, and 50 patients were enrolled after receiving written informed consent. Purposive sampling was used to pick the sample for the analysis, which had a cross-sectional study. The women contacted were in the outpatient psychiatric care of the department of Psychiatry and had been diagnosed with depressive disorder during the study period June 2018 to February 2019. Results: Seventy percent of patients were taking selective serotonin reuptake inhibitors (SSRIs), 20 $\%$ were taking tricyclic antidepressants (TCAs), and $10 \%$ were taking other medications such as mirtazapine or desvenlafexine. Within six months, $44 \%$ of patients were on therapy, and $22.0 \%$ had been on treatment for more than two years. Patients taking Escitalopram $(80 \%)$ have less sexual activity than those taking Sertraline $(66.7 \%)$ or Fluoxetine $(77.8 \%)$, Patients observed a change in sexual activity in 58 percent of cases, a decrease in sexual desire in $70 \%$ of cases $\left(p=0.000{ }^{*}\right)$, a slight decrease in 14 percent of cases, and a slight decrease in only $8 \%$ of cases $(p=0.0009) .18 \%$ of patients reported a delay in orgasm, with 66 percent reporting a major delay, $8 \%$ reporting a moderate delay, and $8 \%$ reporting a slight delay $(p=0.0001)$. Conclusion: Our findings indicate that sexual dysfunction is common in married female patients taking antidepressants, and that antidepressants affect both aspects of sexual functioning.

Key words: Antidepressants; Desire; Orgasm; SSRI's; TCA's

\section{Access this article online}

\section{Website:}

http://nepjol.info/index.php/AJMS DOI: 10.3126/ajms.v12i10.38883 E-ISSN: $2091-0576$ P-ISSN: 2467-9100

Copyright (c) 2021 Asian Journal of Medical Sciences

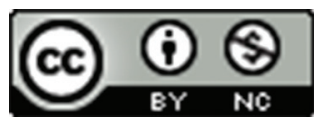

This work is licensed under a Creative Commons Attribution-NonCommercial 4.0 International License.

\section{INTRODUCTION}

Clinicians and patients now have a wide range of antidepressants to choose from, thanks to an ever-growing pharmacopoeia. However, one of the most significant factors preventing antidepressant use is their side effects, one of which is sexual dysfunction. This concern has a negative effect on the patient's quality of life which can contribute to clinical non-adherence in long-term therapies. ${ }^{1}$ Sexual dysfunction has been identified as a possible side effect in both antidepressant types (MAOIs, TCAs, SSRIs, SNRIs and newer antidepressants). ${ }^{2}$

Address for Correspondence:

Dr. Vivek Pratap Singh, Senior Resident, Department of Psychiatry, Patna Medical College and Hospital, Patna, Bihar. 800020

Mobile No: +91-8378897169, Email Id: dearvivekpratapsingh@gmail.com 
The incidences and prevalence rates of sexual dysfunctions have ranged considerably between trials, reflecting variations in methods such as the type of trial, the clinical condition for which the medications were administered, the baseline monitoring, and so on. In addition, there are evaluation approaches such as random reporting, open-ended queries, and validated assessment techniques. However, the common opinion is that patients taking selective serotonin reuptake inhibitors (SSRI), ${ }^{3}$ and monoamine oxidase inhibitors have a large rate of sexual dysfunction (range 30-65\%). (MAOI). ${ }^{4}$

Further research suggests that some antidepressants impair sexual functioning at all stages of the sexual cycle. ${ }^{5}$ Antidepressants such as mirtazapine, reboxetine, bupropion, and moclobemide have been linked to lower rates of sexual dysfunction (ranging from $0 \%$ to $24 \%)^{6,7}$

In addition to antidepressants, studies have found that a variety of other causes affect the frequency and prevalence of sexual dysfunction in depressed patients. Depressive signs, environmental and social causes, and physical and mental co-morbidities are all examples of these.

Female sexual dysfunction is defined as discomfort encountered by a woman or a couple at any stage of normal sexual activity, such as physical stimulation, desire, preference, arousal, or orgasm, resulting in a variety of distressing sexual health issues such as female sexual interest or arousal disorder, female orgasmic disorder, and genito-pelvic pain or penetration disorder. ${ }^{8}$ Sexual disorder is prevalent in women, and it can have a major effect on a person's sexual life quality and drug adherence. ${ }^{9}$

Indian society is traditionally considered to be conservative in nature, especially with respect to discussion of sexual matters by females. Nevertheless, a recent study from our centre reported that the married females have adequate sexual knowledge and a fairly liberal attitude towards sex. Considering this fact and also the lack of enough data specifically for females, the present research was conducted with the aim to study the Sexual Dysfunction in Married Female Patients on Antidepressants at Presenting in Patna Medical College

Indian culture has a reputation for being conservative, especially when it comes to females discussing sexual matters. Nonetheless, according to a new study conducted by married women have sufficient sexual experience and a fairly liberal outlook toward sex. Due to this fact, as well as a lack of data specifically for females, the current study was conducted with the aim the Sexual Dysfunction in Married Female Patients on Antidepressants at Presenting in Patna Medical College.

\section{MATERIALS AND METHODS}

It was Cross-sectional observational study. The study was conducted in the department of Psychiatry, Patna Medical College and Hospital at Patna after approval from the Institutional Ethical Committee. The Departmental Research Committee accepted the report, and 50 patients were enrolled after receiving written informed consent. Purposive sampling was used to pick the sample for the analysis, which had a cross-sectional study. The women contacted were in the outpatient psychiatric care of the department of Psychiatry and had been diagnosed with depressive disorder during the study period June 2018 to February 2019.

They were informed about the study's intent and given the option to approve or decline participation in the study. They were also told that if they were discovered to have sexual addiction, they would be offered assistance by their practicing doctor, based on their willingness.

Patients were chosen using a convenient sampling method. Female patients who had been on antidepressants for more than 4 to 5 weeks, with or without benzodiazepines, and who had normal sexual function prior to therapy were informed about the study's intent and given the option to participate or not.

\section{Inclusion Criteria}

- Patients with a diagnosis of depressive disorder.

- Female patients who were married and cohabitating with their husbands.

- A stable dose of a single antidepressant for at least 3 months prior.

\section{Exclusion Criteria}

- Female patients, who were single, divorced or separated.

- Those with history of sexual dysfunction either prior to onset of depressive disorder.

- Patients with co-morbid psychiatric disorders.

- Co-morbid diagnosis of substance dependence.

- Consuming alcohol daily.

- Hypertension.

- Diabetes mellitus.

- Thyroid dysfunction,

- Cardiovascular disorders.

- Renal dysfunctions.

- Neurological disorders.

- Patients who had attained menopause were also excluded.

\section{Assessment Tools}

The patients were assessed using the DSM-IV-TR in a different room by a consulting psychiatrist, and all 
sociodemographic correlates were recorded for each patient. The PRsexDQ-salsex scale10 was used to test the patients for sexual dysfunction. ${ }^{10}$ The PRsexDQ-salsex (Psychotrophic-Related Sexual Dysfunction Questionnaire) is a 7-item questionnaire about sexual dysfunction. The first item is a screening item to assess any sort of sexual dysfunction. The second issue investigates whether the patient immediately reveals sexual dysfunction to the psychiatrist.

The following elements measure five aspects of sexual dysfunction: decreased sexual appetite, delayed orgasm or ejaculation, inability to achieve orgasm or ejaculation, difficulties in achieving vaginal lubrication, and the patient's tolerance to sexual dysfunction based on intensity or frequency. The patient's lack of worry, including the presence of some kind of sexual dysfunction, defines good tolerance. Where sexual illness triggers concern or discomfort, but the patient does not plan to stop therapy as a result, the equal tolerance strategy was used. When the patient was really nervous with the side effects and is seriously considering stopping therapy, the low tolerance was used.

\section{Statistical Analysis}

The information was presented in the form of a frequency distribution and percentages. Important variations were found using the Epi cal and chi-square goodness of match test through different sociodemographic correlations, with a p-value of $<0.05$ considered relevant.

\section{RESULTS}

Out of 50 cases, 22 (44\%) were belong in $31-40$ years of age group. $08(16 \%)$ cases were found in $25-30$ years of age group, and $20(40 \%)$ cases were found in $41-45$ years of age group respectively (Table 1 ).

All the patients were married, mostly illiterates $(68 \%)$ and literate $32 \%$, unemployed (82 \%) and employed $18 \%$, belonging to nuclear family ( $84 \%$ ) and joint family $16 \%$, respectively (Table 2).

Out of 50 cases $66 \%$ of patients on treatment qualify for diagnostic criteria (DSM-TR-IV) of Major depressive

\begin{tabular}{lcc}
$\begin{array}{l}\text { Table 1: Age distribution among study } \\
\text { population }(\mathrm{n}=\mathbf{5 0})\end{array}$ & \\
\hline Age group in Year & Frequency & Percentage \\
\hline $25-30$ & 08 & 16.0 \\
$31-40$ & 22 & 44.0 \\
$41-45$ & 20 & 40.0 \\
Total & $\mathbf{5 0}$ & $\mathbf{1 0 0}$ \\
Mean \& SD & \multicolumn{3}{c}{$39.42 \pm 2.14$} \\
\hline
\end{tabular}

disorder followed by Somatization disorder $22 \%$, panic disorder $08 \%$, OCD $04 \%$ and others $02 \%$. We have found $76 \%$ of the females were sexually active, with frequency of sexual activity more than 5 times per month in $57.9 \%$ of females. $31.6 \%$ cases of sexual activity were $3-5$ times in a month and $10.5 \%$ cases of sexual activity were $1-2$ times in a month respectively. Forty-four percent of patents are undergoing treatment for 3 to 6 months, $20 \%$ patients are undergoing treatment 7 to 12 months, $14 \%$ patients are undergoing treatment 13 to 24 months and $22 \%$ patients are undergoing treatment $>24$ months respectively (Table 3).

It was seen that the greatest number of patients were taking anti-depressants SSRIs. i.e. $35(70.0 \%)$ of the cases out of 50.10(20.0\%) patients receiving TCA's and 05(10.0\%) patients received others anti-depressants (Table 4).

In patients treated with SSRIs sexual activity was changed higher in patients taking Escitalopram (80\%), followed by Fluoxetine $(77.8 \%)$, Sertraline (66.7\%), Fluvoxamine $(66.7 \%)$ and Paroxetine (50\%). Regarding TCAs we found sexual activity was changed only in patients taking

\begin{tabular}{lcc}
$\begin{array}{l}\text { Table 2: Distribution demographical } \\
\text { characteristics }(\mathbf{n = 5 0})\end{array}$ & \\
\hline Demographical Characteristics & Frequency & Percentage \\
\hline Literate & 16 & 32.0 \\
Illiterate & 34 & 68.0 \\
Employed & 09 & 18.0 \\
Unemployed & 41 & 82.0 \\
Nuclear & 42 & 84.0 \\
Joint & 08 & 16.0 \\
\hline
\end{tabular}

\begin{tabular}{|c|c|c|}
\hline Depressive disorder & Frequency & Percentage \\
\hline DSM-TR-IV & 33 & 66.0 \\
\hline Somatization disorder & 10 & 22.0 \\
\hline panic disorder & 04 & 8.0 \\
\hline OCD & 02 & 4.0 \\
\hline Others & 01 & 2.0 \\
\hline Total & 50 & 100.0 \\
\hline Sexual activity & Frequency & Percentage \\
\hline Yes & 38 & 76.0 \\
\hline No & 12 & 24.0 \\
\hline \multicolumn{3}{|l|}{ Sexual activity per month } \\
\hline $1-2$ & 04 & 10.5 \\
\hline $3-5$ & 12 & 31.6 \\
\hline$>5$ & 22 & 57.9 \\
\hline \multicolumn{3}{|c|}{ Duration of the treatment } \\
\hline Duration of the treatment & Frequency & Percentage \\
\hline 3 months to 6 months & 22 & 44.0 \\
\hline 7 months to 12 months & 10 & 20.0 \\
\hline 13 months to 24 months & 07 & 14.0 \\
\hline$>24$ months & 11 & 22.0 \\
\hline Total & 50 & 100.0 \\
\hline
\end{tabular}


Prothiaden (40\%) no sexual activity was changed in patients taking Clomipramine and Imipramine. Miratazapine showed change in sexual activity in $33.3 \%$ patients. Patients taking Desvenlafaxine showed no change in sexual activity (Table 5).

Seventy percent of patients were taking selective serotonin reuptake inhibitors (SSRIs), $20 \%$ were taking tricyclic antidepressants (TCAs), and $10 \%$ were taking other medications such as mirtazapine or desvenlafexine. Within six months, $44 \%$ of patients were on therapy, and $22.0 \%$ had been on treatment for more than two years. Patients taking Escitalopram $(80 \%)$ have less sexual activity than those taking Sertraline $(66.7 \%)$ or Fluoxetine $(77.8 \%$ ), Patients observed a change in sexual activity in 58 percent of cases, a decrease in sexual desire in $70 \%$ of cases $(p=0.0009 *)$, a slight decrease in 14 percent of cases, and a slight decrease in only $8 \%$ of cases $(p=0.0009 *) .18 \%$ of patients reported a delay in orgasm, with 66 percent reporting a major delay, $8 \%$ reporting a moderate delay, and $8 \%$ reporting a slight delay $(p=0.0001 *)$. Only $20 \%$ of patients were able to experience orgasm. Obtaining vaginal lubrication is difficult for $20 \%$ of patients $(\mathrm{p}=0.0001 *)$. Out of the $40 \%, 28 \%$ have tolerated the problem well, $24 \%$ have complained that the dysfunction bothers them despite continuing their medication as normal, and only $8 \%$ have not tolerated the dysfunction and have had it discontinued (Table 6).

\section{DISCUSSION}

The bulk of trials that have looked at sexual dissatisfaction among antidepressant patients have used a diverse population of both genders and haven't looked at other

\begin{tabular}{lcc} 
Table 4: Type of anti-depressants & \\
\hline Type of Anti-Depressants & Frequency & Percentage \\
\hline SSRI's & 35 & 70.0 \\
TCA's & 10 & 20.0 \\
Others & 05 & 10.0 \\
Total & 50 & 100.0 \\
\hline
\end{tabular}

causes including psychopathology that may lead to sexual dysfunction when on antidepressants. Some of these findings focused on inaccurate and unvalidated measures of sexual dysfunction, such as random reporting, openended questions, or unreliable and unvalidated measures of sexual dysfunction.

It was Cross-sectional observational study. The study was conducted in the department of Psychiatry, Patna Medical College and Hospital at Patna. The Departmental Research Committee accepted the report, and 50 patients were enrolled. Married women who were sexually active (42\%) or inactive (58\%). Other studies ${ }^{11-13}$ have discovered similar findings. However, only $12 \%$ of patients spontaneously reported sexual dysfunction, while the majority did so after being asked questions about sexual dysfunction using a validated sexual function-specific instrument, and the outcome matched previous studies. ${ }^{11}$ This may be due to cultural factors, ${ }^{14}$ as all patients were females, married, and unemployed, with a mean age of 39.422 .14 years.

In this study majority patients were married, with the majority of them being illiterates (68\%) and unemployed (82\%) and belonging to a nuclear family (84 percent). Illiterates from a nuclear household with a social status of class IV. Sexual desire dysfunction was the most common among the multiple domains, followed by orgasmic dysfunction and difficulty obtaining vaginal lubrication. This is in concurrence with the study reported by Grover et al. ${ }^{15}$ The lack of a correlation between antidepressantrelated sexual dysfunction and most sociodemographic and clinical variables in this sample indicates that the incidence of sexual dysfunction can be due to antidepressants alone at best. Female sexual dysfunction is age-related and egalitarian, according to Berman et al., ${ }^{16}$ Montejo et al., ${ }^{17}$ found a similarity between patient age and a lower tolerance for sexual dysfunction, suggesting that when a patient gets older, he or she becomes more anxious with sexual dysfunction.

\section{Table 5: Sexual dysfunction on antidepressant used of SSRI's, TCA,s and others}

\begin{tabular}{|c|c|c|c|c|}
\hline SSRI's ( $n=35)$ & No of Cases Antidepressant Used & Sexual Activity Change & No Change Sexual Activity & P Value \\
\hline Escitalopram & $15(42.9 \%)$ & $12(80 \%)$ & $3(20 \%)$ & $0.001^{*}$ \\
\hline Fluoxetine & $9(25.7 \%)$ & $7(77.8 \%)$ & $2(22.2 \%)$ & $0.029^{*}$ \\
\hline Sertraline & $6(17.1 \%)$ & $4(66.7 \%)$ & $2(33.3 \%)$ & 0.281 \\
\hline Fluvoxamine & $3(8.5 \%)$ & $2(66.7 \%)$ & $1(33.3 \%)$ & 0.499 \\
\hline Paroxetine & $2(5.7 \%)$ & $1(50 \%)$ & $1(50 \%)$ & 0.158 \\
\hline TCA's $(n=10)$ & No of Cases antidepressant used & Sexual activity Change & No change sexual activity & P Value \\
\hline Clomipramine & $3(30 \%)$ & 0 & $3(100 \%)$ & $0.05^{*}$ \\
\hline Imipramine & $2(20 \%)$ & 0 & $2(100 \%)$ & 0.15 \\
\hline Others $(n=5)$ & No of Cases antidepressant used & Sexual activity Change & No change sexual activity & P Value \\
\hline Miratazapine & $3(60 \%)$ & $1(33.3)$ & $2(66.7)$ & 0.49 \\
\hline Desvenlafaxine & $2(40 \%)$ & 0 & $2(100 \%)$ & 0.15 \\
\hline
\end{tabular}




\begin{tabular}{|c|c|c|c|}
\hline \multicolumn{4}{|c|}{$\begin{array}{l}\text { Table 6: Nature of sexual dysfunction among } \\
\text { study population }\end{array}$} \\
\hline \multicolumn{4}{|c|}{ Decrease in Sexual desire } \\
\hline 0 & $18(36 \%)$ & Chi-Square- 16.4 & $p<0.0009$ \\
\hline 1 & $04(8 \%)$ & & \\
\hline 2 & $07(14 \%)$ & & \\
\hline 3 & $21(42 \%)$ & & \\
\hline \multicolumn{4}{|c|}{ Delay in Orgasm } \\
\hline 0 & $33(66 \%)$ & Chi-Square- 46.16 & $p<0.0001$ \\
\hline 1 & $04(8 \%)$ & & \\
\hline 2 & $04(8 \%)$ & & \\
\hline 3 & $09(18 \%)$ & & \\
\hline \multicolumn{4}{|c|}{ Unable to attain orgasm } \\
\hline 0 & $42(84 \%)$ & Chi-Square- 93.2 & $p<0.0001$ \\
\hline 1 & $04(8 \%)$ & & \\
\hline 2 & $01(2 \%)$ & & \\
\hline 3 & $03(6 \%)$ & & \\
\hline \multicolumn{4}{|c|}{ Vaginal lubrication } \\
\hline 0 & $40(80 \%)$ & Chi-Square- 81.6 & $p<0.0001$ \\
\hline 1 & $06(12 \%)$ & & \\
\hline 2 & $03(6 \%)$ & & \\
\hline 3 & $01(2 \%)$ & & \\
\hline \multicolumn{4}{|c|}{ Tolerance } \\
\hline 0 & $20(40 \%)$ & Chi-Square- 10.48 & $p<0.01$ \\
\hline 1 & $14(28 \%)$ & & \\
\hline 2 & $12(24 \%)$ & & \\
\hline 3 & $04(8 \%)$ & & \\
\hline
\end{tabular}

We have found in 50 cases, $66 \%$ of patients on care meet the diagnosis criteria for major depressive disorder (DSMTR-IV), followed by somatization disorder (22\%), panic disorder $(8 \%), \mathrm{OCD}(4 \%)$, and others $(2 \%)$. We discovered that 76 percent of females were sexually active, with 57.9 $\%$ of females experiencing sexual intercourse more than 5 days a month. Sexual activity occurred 3-5 times a month in 31.6 percent of cases and 10.5 percent of cases in 1-2 days a month in 10.5 percent of cases. 44 percent of patents are undergoing treatment for 3 to 6 months, 20 $\%$ are undergoing treatment for 7 to 12 months, $14 \%$ are undergoing treatment for 13 to 24 months, and $22 \%$ are undergoing treatment for more than 24 months.

Antidepressants disrupt sexual functioning in all stages of the sexual response cycle, according to these findings. ${ }^{15}$ Patients taking serotonin reuptake inhibitors (SSRIs) have the highest rate of sexual dysfunction, with up to 80.0 percent of patients showing a reduction in sexual dysfunction, which is consistent with the findings of other studies. ${ }^{5}$

Patients taking Escitalopram (80 percent) had more improvements in sexual behavior than people taking Fluoxetine $(77.8 \%$ ), Sertraline (66.7 percent), Fluvoxamine (66.7 percent), and Paroxetine (66.7 percent) (50 percent). In the case of TCAs, we discovered that sexual behavior was altered only in patients taking Prothiaden (40\%) and not in patients taking Clomipramine or Imipramine. In 33.3 percent of patients, miratazapine caused a decrease in sexual behavior. Sexual intercourse was unaffected in Desvenlafaxine patients.

Similar study by Grover et al., found that $46.63 \%$ of SSRI patients, $50 \%$ of SNRI patients, $42.85 \%$ of TCA patients, and $16.66 \%$ of mirtazapine patients had sexual dysfunction. These numbers are in accordance with what has been reported with this antidepressants. ${ }^{17}$

Patients taking Escitalopram had more sexual dysfunction than those taking Venlafaxine, Paroxetine, Desvenlafaxine, Sertraline, Fluvoxamine, Fluoxetine, Clomipramine, Mirtazapine, Prothiaden, and Imipramine, according to Montgomery SA et al. ${ }^{18}$ The majority of TCA users reported a decrease in sexual desire, orgasmic delay was common among SSRI users, and difficulty achieving vaginal lubrication was common among SNRI users. Similar research has discovered that selective serotonin reuptake inhibitors and serotonin noradrenaline reuptake inhibitors suppress desire, cause erectile dysfunction, and reduce vaginal lubrication.

Patients' orgasm is also affected. ${ }^{19}$ This side effect is used in medicine to prevent premature ejaculation. Sexual desire and orgasm are inhibited by tricyclic antidepressants. ${ }^{18}$

\section{Limitations of the study}

The limited sample size and cross-sectional nature of this analysis restrict its results. It only looked at married female patients who were seeking antidepressants with an underlying psychiatric disorder at a tertiary care hospital. We didn't try to evaluate the couple's marital transition until they started antidepressants, and we didn't gather any clear evidence on disagreements between the couples on different topics. The impact of antidepressant-related sexual dysfunction on care completion and adherence, marriage transition, and partner anxiety was not investigated.

The prevalence rates observed in this research cannot be extended since there were very few patients on any of the antidepressants.

\section{CONCLUSION}

Our findings indicate that sexual dysfunction is common in married female patients taking antidepressants, and that antidepressants affect both aspects of sexual functioning.

\section{ACKNOWLEDGEMENT}

The authors take this opportunity to thank Department of Psychiatry for their whole hearted support for this study. 


\section{REFERENCES}

1. Montejo-González AL, Llorca G, Izquierdo JA, Ledesma A Bousoño M, Calcedo A, et al. Fluoxetine, paroxetine, sertraline, and fluvoxamine in a prospective, multicenter, and descriptive clinical study of 344 patients. Sex Marital Ther. 1997; 23(3):176-194. https://doi.org/10.1080/00926239708403923

2. Montgomery SA, Baldwin DS and Riley A. Antidepressant medications: A review of the evidence for drug-induced sexual dysfunction. J Affect Disord. 2002; 69:119-140.

https://doi.org/10.1016/S0165-0327(01)00313-5

3. Kennedy SH, Eisfeld BS, Dickens SE, Bacchiochi JR and Bagby RM. Antidepressant-induced sexual dysfunction during treatment with moclobemide, paroxetine, sertraline, and venlafaxine. J Clin Psychiatry. 2000; 61:276-281.

https://doi.org/10.4088/JCP.v61n0406

4. Harrison WM, Rabkin JG, Ehrhardt AA, Stewart JW, McGrath PJ, Ross D, et al. Effects of antidepressant medication on sexual function: A controlled study. J Clin Psychopharmacol. 1986; 6:144-149.

https://doi.org/10.1097/00004714-198606000-00004

5. Outhoff K. Antidepressant-induced sexual dysfunction. SA Fam Pract. 2009; 51:298-302.

https://doi.org/10.1080/20786204.2009.10873868

6. Clayton $\mathrm{AH}$, Pradko $\mathrm{J}$ and Croft $\mathrm{H}$. Prevalence of sexual dysfunction among newer antidepressants. J Clin Psychiatry. 2002; 63:357-366.

https://doi.org/10.4088/JCP.v63n0414

7. Clayton AH and Montejo A. Major depressive disorder, antidepressants and sexual dysfunction. J Clin Psychiatry. 2006; 67 Suppl 6:33-37

https://doi.org/10.3810/pgm.2014.03.2744

8. Nolen-Hoeksema, Susan. Abnormal Psychology. 2 Penn Plaza, New York, NY 10121: McGraw-Hill. 2014: pp. 366-367.

https://doi.org/10.29161/PT.v7.i1.2019.11

9. Eden KJ and Wylie KR. Quality of sexual life and menopause. Women's Health. 2009; 5:385-396.

https://doi.org/10.2217/WHE.09.24

10. Grover S and Shouan A. Assessment Scales for Sexual Disorders: A Review. Journal of Psychosexual Health. 2020; 2(2):121-138. https://doi.org/10.1177/2631831820919581

11. Montejo AL and Rico-Villademoros F. Psychometric properties of the Psychotropic-Related Sexual Dysfunction Questionnaire (PRSexDQ-SALSEX) in patients with schizophrenia and other psychotic disorders. Journal of Sex and Marital Therapy. 2008; 34:227-239.

https://doi.org/10.1080/00926230701866125

12. Clayton $\mathrm{AH}$, Pradko $\mathrm{J}$ and Croft $\mathrm{H}$. Prevalence of sexual dysfunction among newer antidepressants. J Clin Psychiatry. 2002; 63:357-366.

https://doi.org/10.4088/JCP.v63n0414

13. Zajecka J, Mitchell $\mathrm{S}$ and Fawcett J. Treatment-emergent changes in sexual function with selective serotonin reuptake inhibitors as measured with the Rush Sexual Inventory. Psychopharmacol Bull. 1997; 33:755-760. https://doi.org/10.4103/0253-7176.106047

14. Avasthi A, Kaur R, Prakash O, Banerjee A, Kumar Land Kulhara P. Sexual behavior of married young women: A preliminary study from North India. Indian J Comm Med. 2008; 33:163-167. https://doi.org/10.4103/0970-0218.39677

15. Grover S, Shah R, Dutt A and Avasthi A. Prevalence and pattern of sexual dysfunction in married females receiving antidepressants: An exploratory study. Journal of Pharmacology and Pharmacotherapeutics. 2012;3 (3): 259-265. https://doi.org/10.4103/0976-500X.99430

16. Berman JR, Berman L and Goldstein Al. Female sexual dysfunction: Incidence, pathophysiology, evaluation and treatment options. Urology. 1999; 54:385-391. https://doi.org/10.1016/S0090-4295(99)00230-7

17. Montejo $\mathrm{AL}$, Prieto $\mathrm{N}$, de Alarcón $\mathrm{R}$, Casado-Espada $\mathrm{N}$, de la Iglesia $\mathrm{J}$ and Montejo L. Management Strategies for Antidepressant-Related Sexual Dysfunction: A Clinical Approach. J Clin Med. 2019; 8(10):1640. https://doi.org/10.3390/jcm8101640

18. Montgomery SA, Baldwin DS and Riley A. Antidepressant medications: A review of the evidence for drug-induced sexual dysfunction. J Affect Disord. 2002; 69:119-140. https://doi.org/10.1016/S0165-0327(01)00313-5

19. Bostwick JM. A generalist's guide to treating patients with depression with an emphasis on using side effects to tailor antidepressant therapy. Mayo Clin Proc. 2010; 85:538-550. https://doi.org/10.4065/mcp.2009.0565

\section{Authors Contribution:}

VPS-Concept and design of the study; prepared first draft of manuscript; APS- Interpreted the results; reviewed the literature and manuscript preparation;

NPS- Concept, coordination, review of literature and manuscript preparation; APS- Statistically analysed and interpreted, preparation of manuscript and revision of the manuscript

\section{Work attributed to:}

Patna Medical College and Hospital, Patna, Bihar. India

Orcid ID:

Dr. Vivek Pratap Singh - (i) https://orcid.org/0000-0002-6780-2484

Dr. Abhishek Pratap Singh - (1) https://orcid.org/0000-0003-1893-0305

Dr. Narendra Pratap Singh - (1) https://orcid.org/0000-0002-6997-5311

Source of Support: Nil, Conflict of Interest: None declared. 